\title{
A deep learning approach for dental implant planning in cone-beam computed tomography images
}

\author{
Sevda Kurt Bayrakdar ${ }^{1}$, Kaan Orhan ${ }^{2,3^{*}}$, Ibrahim Sevki Bayrakdar ${ }^{4,5}$, Elif Bilgir ${ }^{4}$, Matvey Ezhov ${ }^{6}$,
} Maxim Gusarev ${ }^{6}$ and Eugene Shumilov ${ }^{6}$

\begin{abstract}
Background: The aim of this study was to evaluate the success of the artificial intelligence (Al) system in implant planning using three-dimensional cone-beam computed tomography (CBCT) images.

Methods: Seventy-five CBCT images were included in this study. In these images, bone height and thickness in 508 regions where implants were required were measured by a human observer with manual assessment method using InvivoDental 6.0 (Anatomage Inc. San Jose, CA, USA). Also, canals/sinuses/fossae associated with alveolar bones and missing tooth regions were detected. Following, all evaluations were repeated using the deep convolutional neural network (Diagnocat, Inc., San Francisco, USA) The jaws were separated as mandible/maxilla and each jaw was grouped as anterior/premolar/molar teeth region. The data obtained from manual assessment and Al methods were compared using Bland-Altman analysis and Wilcoxon signed rank test.
\end{abstract}

Results: In the bone height measurements, there were no statistically significant differences between Al and manual measurements in the premolar region of mandible and the premolar and molar regions of the maxilla $(p>0.05)$. In the bone thickness measurements, there were statistically significant differences between Al and manual measurements in all regions of maxilla and mandible $(p<0.001)$. Also, the percentage of right detection was $72.2 \%$ for canals, $66.4 \%$ for sinuses/fossae and $95.3 \%$ for missing tooth regions.

Conclusions: Development of Al systems and their using in future for implant planning will both facilitate the work of physicians and will be a support mechanism in implantology practice to physicians.

Keywords: Artificial intelligence, Dental implant, Implant planning, Dentistry

\section{Background}

Dental implants have been preferred by clinicians for many years in cases of the total, partial and single-tooth edentulism [1-3]. Detailed planning before the implant operation increases the success of the treatment due to the facility of placing in the correct position of the

\footnotetext{
*Correspondence: call53@yahoo.com

2 Department of Oral and Maxillofacial Radiology, Faculty of Dentistry,

Ankara University, 06500 Ankara, Turkey

Full list of author information is available at the end of the article
}

implant and eliminating the surgical risks [4-6]. For this purpose, in implant surgery, the various radiographic techniques are used to evaluate alveolar bone features (bone quality, thickness, and height) and anatomical variations in the operation area (such as nasal fossa, mandibular canal, mental foramen and sinuses) $[4,5,7]$.

Panoramic and intraoral radiographs are used still in dental implant practices to provide an overview of the jaws and to create a preliminary idea; but these radiographic techniques are insufficient for detailed implant planning $[4,8,9]$. Cross-sectional tomograms such as 
computed tomography (CT) and cone-beam computed tomography (CBCT) which offer three-dimensional (3D) information to surgeons are currently used as an alternative to these conventional techniques [9]. CBCT devices developed for dentomaxillofacial imaging, have more affordable prices and smaller device sizes than CT devices. It also offers high-quality images at a lower radiation dose and short scanning time $[4,9,10]$. It is known that $\mathrm{CBCT}$ devices are very successful in determining the ideal implant sizes (i.e., length and width) before the operation and in predicting the necessary extra surgical procedures (i.e., guided tissue regeneration, splitting, sinus elevation) in case of insufficient bone in the operation site $[4,5,7,11]$. Nevertheless, the physician's knowledge, skills, and experience in the interpretation of CBCT images also play very great roles in performing detailed implant planning [12].

Artificial intelligence (AI) is a field of computer science aimed at performing various specific functions that require human intelligence. It imitates human intelligence and improves its these features acquired over time using the deep learning methods [13]. In radiological diagnostic clinics, using the AI has provided to emerge the computer-aided diagnosis (CAD) systems. Then the development of this system has gained momentum in many fields of medicine and its use also has become widespread in health sectors such as dentistry in recent years $[14,15]$. A deep convolutional neural network method (DCNN) is a powerful deep learning application used on medical diagnostic images [16, 17]. There are studies in the literature where this method, which also enables the processing of more complex images such as CBCT images, has used in various diagnostics in dentistry such as tooth numbering, periapical pathosis, and mandibular canal detection [18-21].

Many specialists and general practitioners have not received extensive training on radiographic image evaluation and not competent in detailed implant planning and interpretation of anatomical data [10,22]. This is a situation that makes challenges of dentistry practice and still awaits a solution. Using AI systems in radiographic interpretation provides many advantages to the physician and can contribute to solving this problem. Also, it may prevent wrong diagnosis and treatment planning (which may be due to work intensity, carelessness or inexperience), unnecessary loss of time/workload in dentistry [12].

To our best knowledge, there are no studies in the literature where AI systems are used in implant planning. The purpose of this study was to verify the diagnostic performance and assess the reliability of an artificial intelligence system based on the deep convolutional neural network method to implant planning in CBCT images.

\section{Methods}

\section{Patient selection and imaging}

A total of 75 patients' (cases with implant indication and recorded in 2019) CBCT images obtained from the CBCT archive of the Faculty of Dentistry of Eskissehir Osmangazi University were included in the study. Also, 508 measurements (in areas that have missing teeth and with implant indication) were performed from them. For the study procedures, the Non-interventional Clinical Research Ethics Committee Approval was received and principles of the Declaration of Helsinki were followed at each stage (decision date and number: 08.07.2019 and 2019-220). All images were acquired with the same CBCT scanner (Promax 3D Mid; Planmeca, Helsinki, Finland) and the same conditions. Diagnostic settings were as follows: $94 \mathrm{kVp}, 14 \mathrm{~mA}, 360^{\circ}$ rotation, $27 \mathrm{~s}$.

\section{Evaluation of tomography data}

All images were examined by an oral and maxillofacial radiologist with at least 8 years of professional experience (I.S..B) by converting them to DICOM format. The jaws were separated as mandible/maxilla and each jaw was grouped as anterior/premolar/molar teeth region. Canine teeth and incisors were included in the anterior region. Canals/sinuses/fossae associated with alveolar bones were detected and missing teeth were recorded. In missing teeth areas, bone height and thickness were measured by manual assessment methods using InvivoDental 6.0 (Anatomage Inc. San Jose, CA, USA). In other words, all evaluations were performed as in implant plannings; and limitations of anatomical structures were taken into consideration.

After manual evaluations, all files were randomly uploaded to the deep convolutional neural network (Diagnocat, Inc.) for determinations of canals/sinuses/ fossae and calculation of bone length/width in missing teeth areas. The data obtained from manual assessment and artificial intelligence (AI) methods were compared.

\section{Model pipeline}

Diagnocat AI system prepares an implant planning report based on a pipeline of multiple pre-trained fully convolutional networks and algorithmic slice extraction. Predictions crucial for implant planning include voxelperfect segmentations of teeth, jaws, mandibular canals, maxillary sinuses, and missing teeth.

Missing teeth segmentation relies on both present teeth and jaws segmentations. A missing tooth mask is a virtual tooth mask that is extracted using neighboring teeth location, tilt, and placement according to a jaw. It allows to predict a mesiodistal angle of implant placement and provides a guide to a slicing algorithm. Implant planning study includes a panoramic reformat 
of a specified jaw and a slice section with vestibulooral slice orientation. Teeth, jaws, and mandibular canal segmentations are used to build a panoramic ribbon of both a study image and a combined segmentation mask. All slices in a study are extracted from a region of interest (RoI) of a panoramic image ribbon with a user chosen step, $2 \mathrm{~mm}$ by default, and slice thickness, 1 voxel by default. Predicted target (missing) tooth and neighboring (potentially missing) teeth masks define a RoI and mesiodistal angle of slice extraction showing possible implant placement (Fig. 1).

Every slice has two to three measurements providing information about possible implant size and direction. The first measurement shows a width of alveolar bone. The second measurement shows a distance from the first measurement line to the closest obstacle in implant

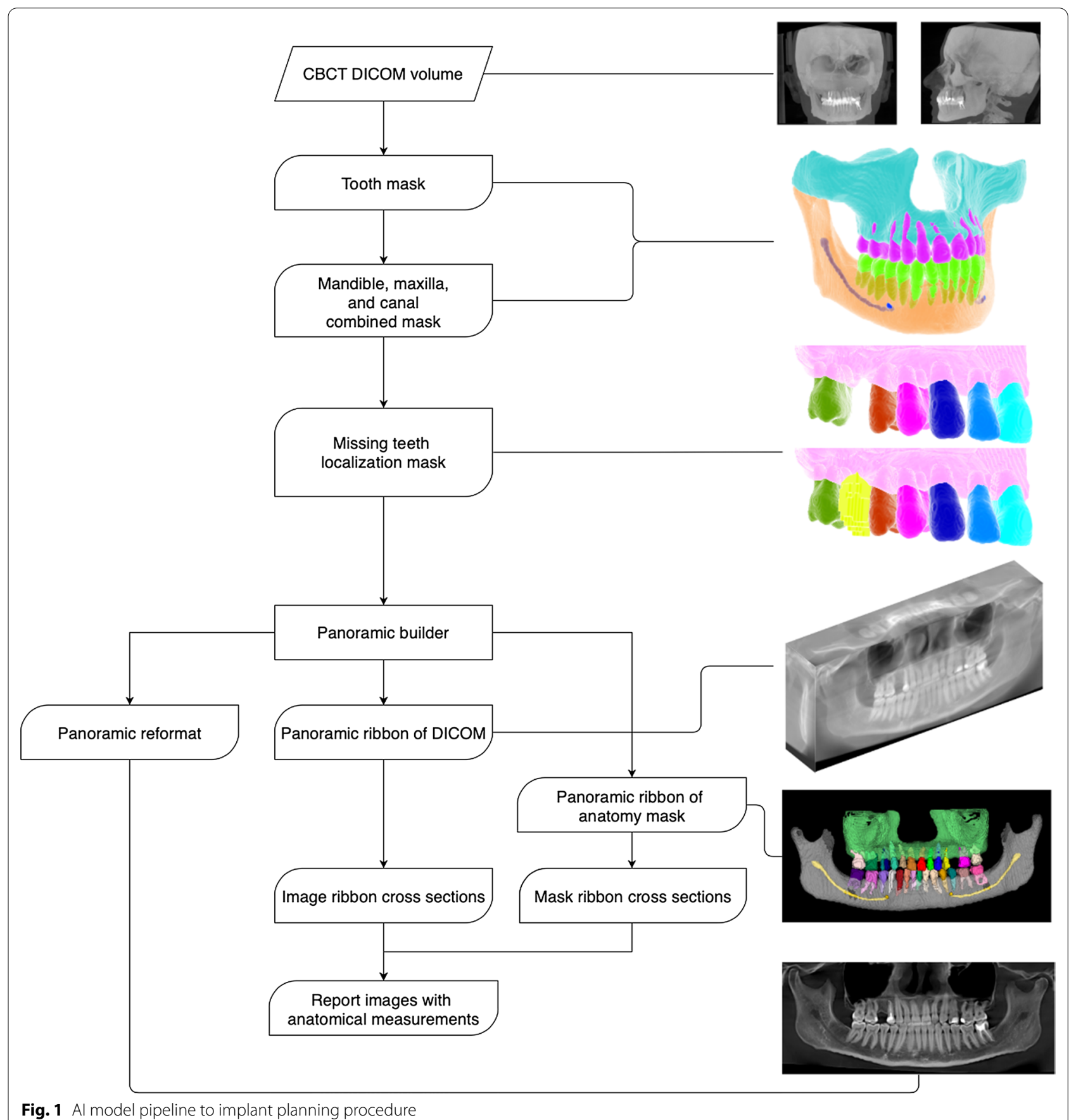


direction which is either of mandibular canal, maxillary sinus, or a jaw bone edge. The third measurement is calculated only in mandible case and shows a vertical distance from an oral end of the first measurement line to a mandible bone edge (Fig. 2).

\section{The architecture of the deep convolutional neural networks}

Diagnocat AI system exploits a set of pre-trained semantic segmentation networks based on internally modified fully convolutional 3D U-Net architecture from [23] to obtain voxel-perfect segmentation masks of present teeth and anatomy elements and to approximate localization of missing teeth.

\section{Examiner consistency}

The measurements were performed by the same examiner. One hundred measurements were repeated 1 week after the first evaluation by the examiner. In this way, intra-examiner agreement and reliability were evaluated using intraclass correlation coefficients and intra-evaluator technical error measurement (TEM) calculations. The intraclass correlation coefficient (95\% confidence interval) was 0.995 (0.992-0.997) for bone thickness; 0.996 (0.994-0.997) for bone height. Also, relative TEM was 3.14 (acceptable) and reliability was $99.5 \%$ for bone thickness measurement, relative TEM was 2.37 (acceptable) and reliability was $99.6 \%$ for bone height measurements.

\section{Statistical analyses}

Statistical analyses were performed with the SPSS 21.0 Package Data Program (SPSS 21.0 Software Package Program, Inc., Chicago, IL). Kolmogorov-Smirnov test was used when testing for normality. A comparison of measurements calculated by manual assessment and artificial intelligence (AI) was made by Wilcoxon signed-rank test and Bland-Altman analysis. A value of $p<0.05$ was considered statistically.

\section{Results}

Correctness frequencies of canal/sinus/fossa/missing tooth detections of the AI system are listed in Table 1. The percentage of right detection was $72.2 \%$ for canals, $66.4 \%$ for sinuses/fossae. Also, it was seen that 484 (95.3\%) of 508 missing tooth regions were detected correctly and only $24(4.7 \%)$ was detected incorrectly.

The values of bone height and thickness measurements with the AI system and manual assessment are shown in Table 2. The AI system was unable to perform 80 of bone height measurements (therefore, bone height measurements evaluated on 428 images) and 15 of bone thickness measurements (therefore, bone thickness measurements evaluated on 493 images).

In the bone height measurements, there were no statistically significant differences between AI and manual measurements in the premolar region of mandible and the premolar and molar regions of the maxilla $(p>0.05)$. In the bone thickness measurements, there were statistically significant differences between AI and manual measurements in all regions of maxilla and mandible $(p<0.001)$. Bland Altman plots for measurements are shown in Figs. 3 and 4. Confidence interval for differences between the manual and AI system are shown in Table 3.
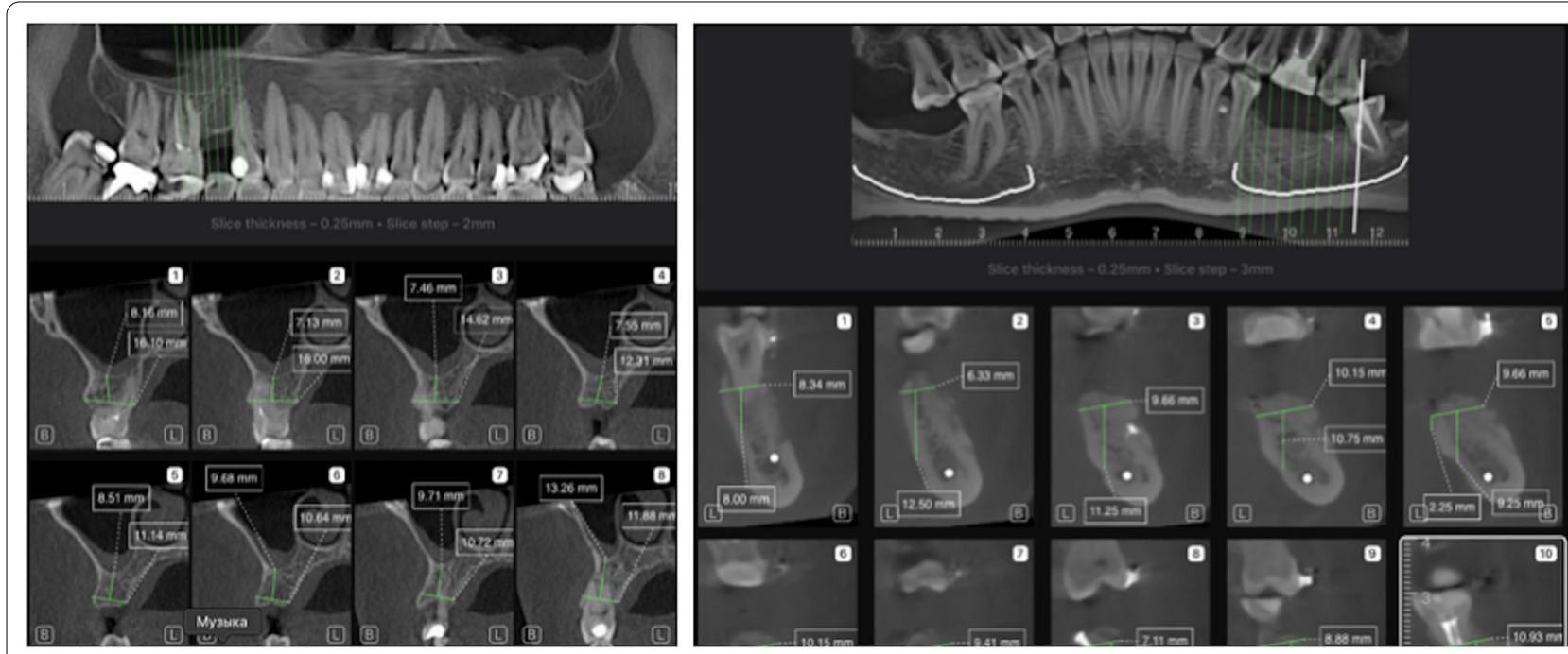

Fig. 2 Implant planning report which was created otomatically for maxilla and mandibula case using the Al 
Table 1 False and right percentages of canal/sinus/fossa detections of the Al system

\begin{tabular}{|c|c|c|c|c|c|c|c|c|}
\hline \multirow[t]{3}{*}{ Regions } & \multicolumn{4}{|c|}{ Canal/sinus/fossa detection $(\%, \mathrm{n})$} & \multicolumn{4}{|c|}{ Missing tooth detection $(\%, \mathrm{n})$} \\
\hline & \multicolumn{2}{|c|}{ Canal detection (Mandibula) } & \multicolumn{2}{|c|}{ Sinus/fossa detection (Maxilla) } & \multicolumn{2}{|c|}{ Mandibula } & \multicolumn{2}{|l|}{ Maxilla } \\
\hline & False & Right & False & Right & False & Right & False & Right \\
\hline Anterior & $\begin{array}{l}83 \% \\
(n=44)\end{array}$ & $\begin{array}{l}17 \% \\
(n=9)\end{array}$ & $\begin{array}{l}91.8 \% \\
(n=56)\end{array}$ & $\begin{array}{c}8.2 \% \\
(n=5)\end{array}$ & $\begin{array}{l}9.4 \% \\
(n=5)\end{array}$ & $\begin{array}{l}90.6 \% \\
(n=48)\end{array}$ & $\begin{array}{l}8.2 \% \\
(n=5)\end{array}$ & $\begin{array}{l}91.8 \% \\
(n=56)\end{array}$ \\
\hline Premolar & $\begin{array}{l}29.5 \% \\
(n=18)\end{array}$ & $\begin{array}{l}70.5 \% \\
(n=43)\end{array}$ & $\begin{array}{l}27.7 \% \\
(n=28)\end{array}$ & $\begin{array}{l}72.3 \% \\
(n=73)\end{array}$ & $\begin{array}{l}3.3 \% \\
(n=2)\end{array}$ & $\begin{array}{l}96.7 \% \\
(n=59)\end{array}$ & $\begin{array}{l}5.9 \% \\
(n=6)\end{array}$ & $\begin{array}{l}94.1 \% \\
(n=95)\end{array}$ \\
\hline Molar & $\begin{array}{c}2.5 \% \\
(n=3)\end{array}$ & $\begin{array}{l}97.5 \% \\
(n=117)\end{array}$ & $\begin{array}{c}7.1 \% \\
(n=8)\end{array}$ & $\begin{array}{l}92.9 \% \\
(n=104)\end{array}$ & $\begin{array}{l}1.7 \% \\
(n=2)\end{array}$ & $\begin{array}{l}98.3 \% \\
(n=118)\end{array}$ & $\begin{array}{l}3.6 \% \\
(n=4)\end{array}$ & $\begin{array}{l}96.4 \% \\
(n=108)\end{array}$ \\
\hline Total & $\begin{array}{l}27.8 \% \\
(n=65)\end{array}$ & $\begin{array}{l}72.2 \% \\
(n=169)\end{array}$ & $\begin{array}{l}33.6 \% \\
(n=92)\end{array}$ & $\begin{array}{l}66.4 \% \\
(n=182)\end{array}$ & $\begin{array}{l}3.8 \% \\
(n=9)\end{array}$ & $\begin{array}{l}96.2 \% \\
(n=225)\end{array}$ & $\begin{array}{l}5.5 \% \\
(n=15)\end{array}$ & $\begin{array}{l}94.5 \% \\
(n=259)\end{array}$ \\
\hline
\end{tabular}

Table 2 Bone height and thickness measurements with the Al system and manual assessment

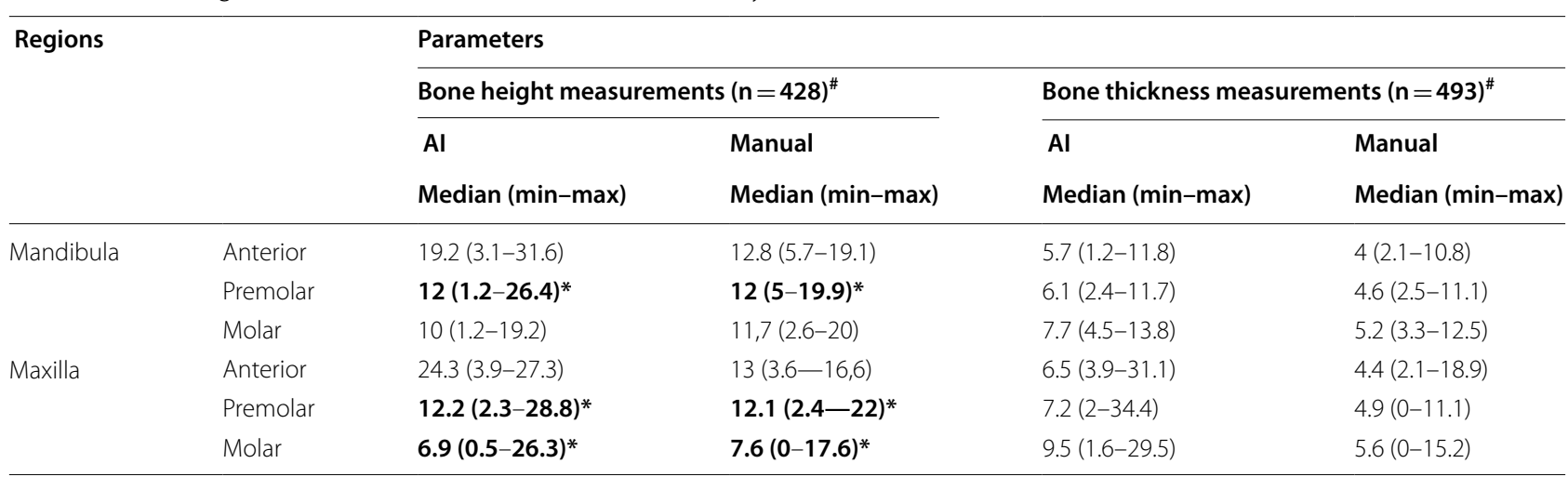

Bold variables in the table indicates no statistical significant difference $(p>0.05)$

*There were no differences between Al and manual measurements for each parameter $(p>0.05)$. Min, minimum; Max, Maximum

\# A total of 508 measurements were performed, but the Al system was unable to perform 80 of bone height measurements and 15 of bone thickness measurements. For each parameter, statistical analyzes were made on the measurements that can only be evaluated with the Al system

\section{Discussion}

In recent years, there has been a significant increase in the number of studies using AI for purposes such as disease detection and classification, organ and lesion segmentation in the medicine $[24,25]$. With all these developments, the use of AI systems to interpret radiological images in dental radiology has also become widespread [14, 15, 25]. Using computer-aided systems in imaging techniques that require experience and expertise such as especially CT and CBCT will provide great convenience to physicians. But new academical studies are needed in this regard. In light of all this information, the present study aims the using DCNN during the planning of implants which is a popular treatment option in dentistry practice.

In the literature, there are studies reported the AI systems' using in a variety of dentistry situations such as detecting dental caries [26-29], root fractures [30-32], root morphologies [33], jaw pathologies [34], periodontal bone damages [35-38], periapical lesions [21] and also determinating teeth and their numbering [19, 39]. Analyzes of these studies, which are the pioneers of DCNN applications in dentistry, were made on a wide variety of radiographic imageries such as periapical, panoramic, bitewing cephalometric, CT and CBCT. Nevertheless, it is seen that the number of studies based on CT and CBCT is limited [25]. Johari et al. found that the probabilistic neural network (PNN) method was successful in determining vertical root fractures in their study on CBCT images [31]. Hiraiwa et al., also reported that AI showed acceptable results in determining the extra roots of teeth in CBCT [33]. Also, Orhan et al. reported in their study on periapical lesions in CBCT images that the volume measurements calculated with the convolutional neural network $(\mathrm{CNN})$ method are compatible with manual measurements and this situation are promising for the future [21].

Treatment planning is one of the most important steps of workflow in both medicine and dentistry. For the success in the treatment, the correct diagnosis should be 

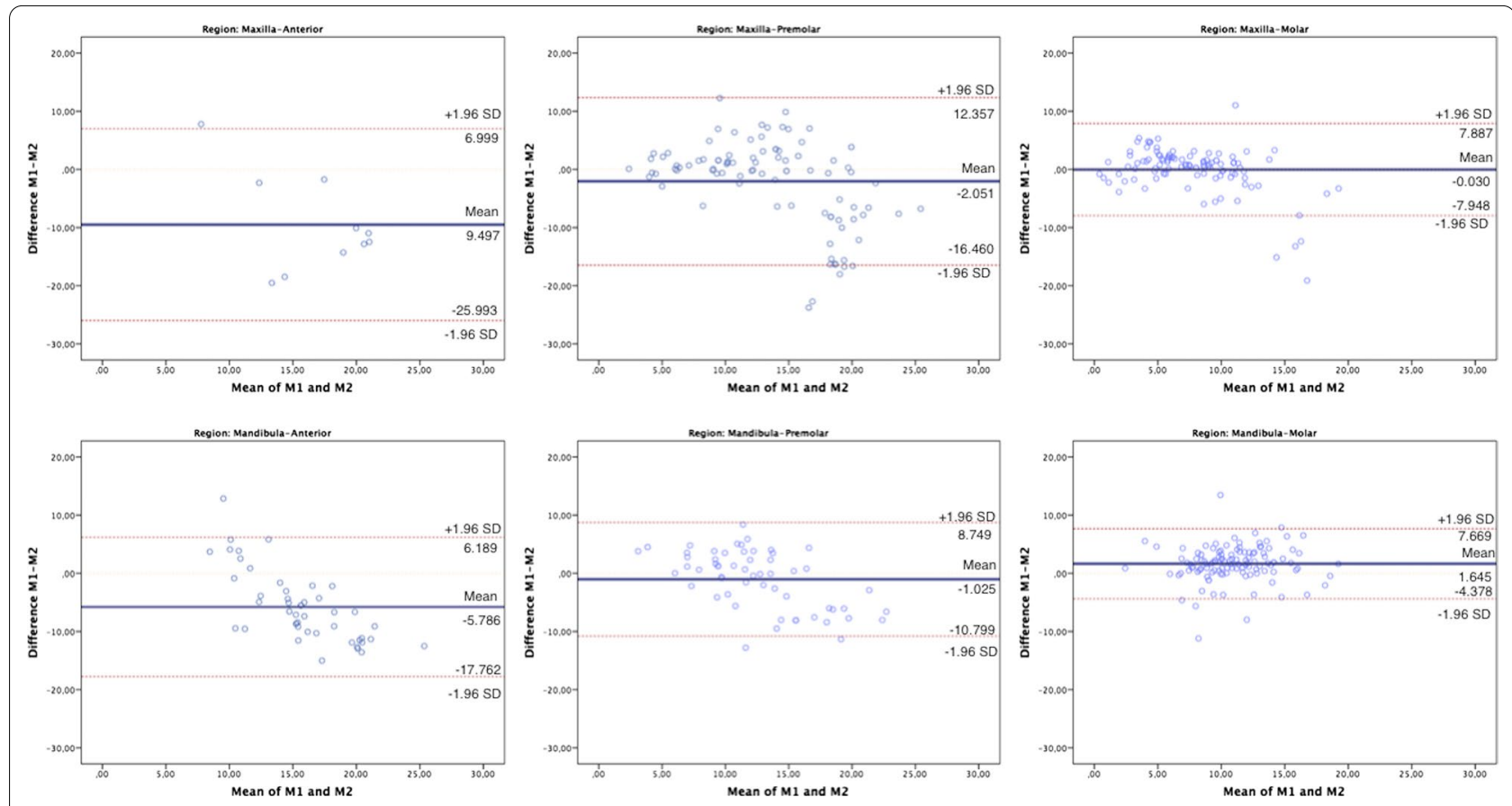

Fig. 3 Bland Altman plots for bone height. M1, Manual measurements; M2, Al measurements

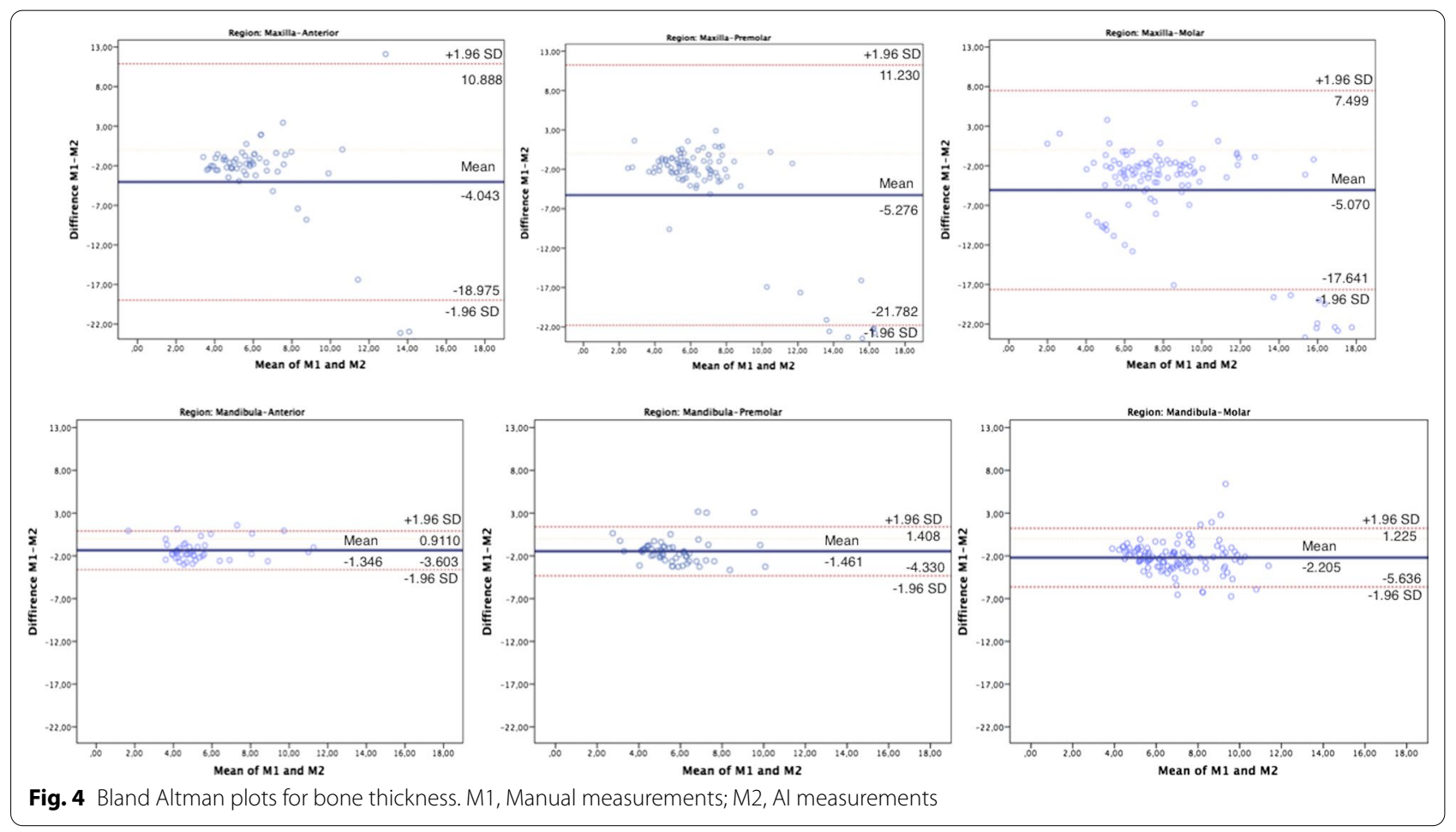

made first, then the ideal treatment planning should be created for the patient. Treatment planning is a detailed organizational process; it depends on many factors such as the physician's knowledge experience [40]. In recent years, artificial intelligence systems have been used to support decision making processes in the diagnosis and 
Table 3 Confidence interval for differences of manual and Al system

\begin{tabular}{|c|c|c|c|c|c|c|c|c|c|c|}
\hline \multirow[t]{3}{*}{ Parameters } & \multirow[t]{3}{*}{ Jaws } & \multirow[t]{3}{*}{ Regions } & \multicolumn{5}{|c|}{ Paired differences } & \multirow[t]{3}{*}{$\mathbf{t}$} & \multirow[t]{3}{*}{ df } & \multirow[t]{3}{*}{ Sig (2-tailed) } \\
\hline & & & \multirow[t]{2}{*}{ Mean } & \multirow[t]{2}{*}{ SD } & \multirow[t]{2}{*}{$\begin{array}{l}\text { Standard } \\
\text { error mean }\end{array}$} & \multicolumn{2}{|c|}{$\begin{array}{l}95 \% \mathrm{Cl} \text { of the } \\
\text { difference }\end{array}$} & & & \\
\hline & & & & & & Lower & Upper & & & \\
\hline \multirow[t]{6}{*}{ Bone height } & \multirow[t]{3}{*}{ Mandibula } & Anterior & -5.79 & 6.11 & 0.89 & -7.58 & -3.99 & -6.49 & 46 & $<0.001$ \\
\hline & & Premolar & -9.50 & 8.42 & 2.66 & -15.52 & -3.48 & -3.57 & 9 & 0,006 \\
\hline & & Molar & -1.02 & 4.99 & 0.66 & -2.35 & 0.30 & -1.55 & 56 & 0,126 \\
\hline & \multirow[t]{3}{*}{ Maxilla } & Anterior & -2.05 & 7.35 & 0.77 & -3.58 & -0.52 & -2.66 & 90 & 0,009 \\
\hline & & Premolar & 1.64 & 3.07 & 0.28 & 1.08 & 2.20 & 5.81 & 117 & $<0.001$ \\
\hline & & Molar & -0.03 & 4.04 & 0.39 & -0.81 & 0.75 & -0.08 & 104 & 0,938 \\
\hline \multirow[t]{6}{*}{ Bone thickness } & \multirow[t]{3}{*}{ Mandibula } & Anterior & -1.35 & 1.15 & 0.17 & -1.68 & -1.00 & -8.01 & 46 & $<0.001$ \\
\hline & & Premolar & -4.04 & 7.62 & 0.97 & -5.99 & -2.09 & -4.14 & 60 & $<0.001$ \\
\hline & & Molar & -1.46 & 1.46 & 0.19 & -1.85 & -1.07 & -7.53 & 56 & $<0.001$ \\
\hline & \multirow[t]{3}{*}{ Maxilla } & Anterior & -5.28 & 8.42 & 0.84 & -6.95 & -3.60 & -6.26 & 99 & $<0.001$ \\
\hline & & Premolar & -2.20 & 1.75 & 0.16 & -2.52 & -1.89 & -13.68 & 117 & $<0.001$ \\
\hline & & Molar & -5.07 & 6.41 & 0.61 & -6.28 & -3.86 & -8.29 & 109 & $<0.001$ \\
\hline
\end{tabular}

Cl confidence interval

treatment planning of physicians. The neural network machine learning system was used in various treatment plans such as radiation therapy and orthognathic surgery and promising results were obtained [40-42]. As it is known, radiographic imaging plays an important role in the planning of dental implants. It is recommended to examine the operation site with 3-dimensional imaging systems before the operation and to make detailed planning by performing a series of measurements under conditions permitted by anatomic variations [5]. Formations such as mandibular canal, sinuses and nasal fossa evaluated in the current study are the main anatomic variations that shape the implant planning. Kwak et al. recently reported successful results in determining the mandibular canal by the CNN method in CBCT images and stated that this may be an opportunity for future dental planning [18]. Similarly, Fukuda et al. evaluated the relationship between the 3rd mandibular molar tooth and the mandibular canal in their study on 600 panoramic radiographs [43]. Jaskari et. al have used the $\mathrm{CNN}$ method for mandibular canal segmentation in al CBCT images. They stated that AI systems give sensitive and reliable results in canal determination and these systems may be an important role in future implant planning [44]. The results of our study were similar to these studies; and its success percentage was $97.9 \%$ in the mandibular canal detection.

In the present study, sinus/fossa and missing teeth detection analysis were also performed, and it was observed that AI systems showed a success of $66.4 \%$ and $95.3 \%$, respectively. It is seen that the number of studies regarding the detection of nasal fossa should be increased and the system should be improved. Because, as the success of the detection of anatomic structures in AI systems increases, the measurements made for implant planning will yield more successful results. To our best knowledge, there is no study in the literature for the determination of lost tooth/fossa and sinus, this is the first study on this subject. However, one study for determining sinus pathologies on panoramic images has been carried out and successful results of AI have been reported [45].

In this study, two separate measurements, bone thickness, and height were performed to evaluate the success of implant planning. The results of the study show that bone thickness measurements of AI should be improved using a deep learning system. We think this may be due to the measurement of the AI system with incorrect angles when evaluating bone thickness measurements. In the determination of nasal fossa in the maxilla and mandibular accessory canals in the mandibula, the system was not very sensitive; this situation caused some incompatibilities in the anterior region bone height measurements.

While the determination of the mandibular canal was successful, it is found that the bone height could not be determined correctly in these regions. We think that this may be because the system did not take into account the implant diameter and thickness. This deficiency may cause the system to bypass the canal from the buccal/ lingual of the canal during measurement. As a result, the AI system can report measurements in this region higher than they should. 
However, it is seen that the results of the AI system consistent with the manual measurements in the maxilla molar/premolar region, as well as in the mandible premolar region; these results offer hope for the usability of the system in implant planning.

\section{Conclusion}

Consequently, using these systems in implant planning will both facilitate the work of physicians and will be a support mechanism in implantology practice. The success of the present study in the detection of sinus / mandibular canal and missing teeth and the measurements it offers in implant planning reinforces this possibility. There is a need for more extensive studies in which environmental anatomical formations are evaluated by AI for the development of CNN systems in implant planning.

\begin{abstract}
Abbreviations
Al: Artificial intelligence; CBCT: Cone-beam computed tomography; CT: Computed tomography; 3D: Three-dimensional; CAD: Computer-aided diagnosis; DCNN: Deep convolutional neural network; TEM: Technical error measurement; PNN: Probabilistic neural network; CNN: Convolutional neural network.
\end{abstract}

\section{Acknowledgements}

Not applicable.

\section{Authors' contributions}

SKB Conceptualization, Writing of the original draft, KO Project administration, Review, and editing, ISB Investigation, Writing of the original draft, EB Investigation, Writing of the original draft, ME Conceptualization, Methodology, MG Conceptualization, Methodology, ES Conceptualization, Methodology. All authors read and approved the final manuscript.

\section{Funding}

This research received no specific grant from any funding agency in the public, commercial, or not-for-profit sectors.

\section{Availability of data and materials}

Not applicable.

\section{Declarations}

\section{Ethics approval and consent to participate}

The research protocol was approved by the Eskisehir Osmangazi University Ethics Committee. All participants gave informed consent. We confirmed that the study were carried out in accordance with relevant guidelines and regulations of Helsinki Declaration.

\section{Consent for publication}

Not applicable.

\section{Competing interests}

The authors declare that there is no conflict of interest.

\section{Author details}

'Department of Periodontology, Faculty of Dentistry, Eskisehir Osmangazi University, Eskişehir, Turkey. ${ }^{2}$ Department of Oral and Maxillofacial Radiology, Faculty of Dentistry, Ankara University, 06500 Ankara, Turkey. ${ }^{3}$ Medical Design Application and Research Center (MEDITAM), Ankara University, Ankara, Turkey. ${ }^{4}$ Department of Oral and Maxillofacial Radiology, Faculty of Dentistry, Eskisehir Osmangazi University, Eskişehir, Turkey. ${ }^{5}$ Eskisehir Osmangazi University Center of Research and Application for Computer Aided Diagnosis and Treatment in Health, Eskisehir, Turkey. ${ }^{6}$ Diagnocat, Inc, San Francisco, USA.

Received: 28 February 2021 Accepted: 5 May 2021

Published online: 19 May 2021

\section{References}

1. Gaviria L, Salcido JP, Guda T, Ong JL. Current trends in dental implants. J Korean Assoc Oral Maxillofac Surg. 2014;40:50-60.

2. Lindh T, Gunne J, Tillberg A, Molin M. A meta-analysis of implants in partial edentulism. Clin Oral Implant Res. 1998:9:80-90.

3. Albrektsson T, Wennerberg A. The impact of oral implants-past and future, 1966-2042. J Can Dent Assoc. 2005;71:327.

4. Correa LR, Spin-Neto R, Stavropoulos A, Schropp L, da Silveira HED, Wenzel A. Planning of dental implant size with digital panoramic radiographs, CBCT-generated panoramic images, and CBCT cross-sectional images. Clin Oral Implant Res. 2014;25:690-5.

5. Worthington P, Rubenstein J, Hatcher DC. The role of cone-beam computed tomography in the planning and placement of implants. J Am Dent Assoc. 2010;141:19S-24S.

6. Gaêta-Araujo H, Oliveira-Santos N, Mancini AXM, Oliveira ML, OliveiraSantos C. Retrospective assessment of dental implant-related perforations of relevant anatomical structures and inadequate spacing between implants/teeth using cone-beam computed tomography. Clin Oral Investig. 2020;24:1-8.

7. Sießegger M, Schneider BT, Mischkowski RA, Lazar F, Krug B, Klesper $B$, et al. Use of an image-guided navigation system in dental implant surgery in anatomically complex operation sites. J Cranio-Maxillofac Surg. 2001;29:276-81.

8. Angelopoulos C, Thomas S, Hechler S, Parissis N, Hlavacek M. Comparison between digital panoramic radiography and cone-beam computed tomography for the identification of the mandibular canal as part of presurgical dental implant assessment. J Oral Maxillofac Surg. 2008;66:2130-5.

9. Suomalainen A, Vehmas T, Kortesniemi M, Robinson S, Peltola J. Accuracy of linear measurements using dental cone beam and conventional multislice computed tomography. Dentomaxillofac Radiol. 2008;37:10-7.

10. Scarfe WC, Farman AG. What is cone-beam CT and how does it work? Dent Clin North Am. 2008;52:707-30.

11. Ekestubbe A, Gröndahl K, Gröndahl H. The use of tomography for dental implant planning. Dentomaxillofac Radiol. 1997;26:206-13.

12. Zakirov A, Ezhov M, Gusarev M, Alexandrovsky V, Shumilov E. Dental pathology detection in 3D cone-beam CT. arXiv preprint arXiv:181010309 2018.

13. Chartrand G, Cheng PM, Vorontsov E, Drozdzal M, Turcotte S, Pal CJ, et al. Deep learning: a primer for radiologists. Radiographics. 2017;37:2113-31.

14. Sen D, Chakrabarti R, Chatterjee S, Grewal D, Manrai K. Artificial intelligence and the radiologist: the future in the Armed Forces Medical Services. BMJ Military Health. 2019;166:254-6.

15. Raja'a M, Farid F. Computer-based technologies in dentistry: types and applications. J Dent. 2016;13:215.

16. Han X. MR-based synthetic CT generation using a deep convolutional neural network method. Med Phys. 2017;44:1408-19.

17. Miki Y, Muramatsu C, Hayashi T, Zhou X, Hara T, Katsumata A, et al. Classification of teeth in cone-beam CT using deep convolutional neural network. Comput Biol Med. 2017;80:24-9.

18. Kwak GH, Kwak E-J, Song JM, Park HR, Jung Y-H, Cho B-H, et al. Automatic mandibular canal detection using a deep convolutional neural network. Sci Rep. 2020;10:1-8.

19. Tuzoff DV, Tuzova LN, Bornstein MM, Krasnov AS, Kharchenko MA, Nikolenko SI, et al. Tooth detection and numbering in panoramic radiographs using convolutional neural networks. Dentomaxillofac Radiol. 2019;48:20180051.

20. Muramatsu C, Kutsuna S, Takahashi R, Hayashi T, Nishiyama W, Ariji Y, et al. Tooth numbering in cone-beam CT using a relation network for automatic filing of dentition charts. Medical Imaging 2020: Imaging Informatics for Healthcare, Research, and Applications: International Society for Optics and Photonics; 2020. p. $113180 \mathrm{~L}$. 
21. Orhan K, Bayrakdar I, Ezhov M, Kravtsov A, ÖzyürekT. Evaluation of artificial intelligence for detecting periapical pathosis on cone-beam computed tomography scans. Int Endod J. 2020;53:680-9.

22. Iannucci J, Howerton LJ. Dental radiography-E-book: principles and techniques. Amsterdam: Elsevier; 2016.

23. Isensee F, Kickingereder P, Wick W, Bendszus M, Maier-Hein KH. Brain tumor segmentation and radiomics survival prediction: contribution to the brats 2017 challenge. In: International MICCAI brainlesion workshop. Springer; 2017. p. 287-97.

24. Lee H, Tajmir S, Lee J, Zissen M, Yeshiwas BA, Alkasab TK, et al. Fully automated deep learning system for bone age assessment. J Digit Imaging. 2017;30:427-41

25. Schwendicke F, Golla T, Dreher M, Krois J. Convolutional neural networks for dental image diagnostics: a scoping review. J Dent. 2019;91:103226.

26. Devito KL, de Souza BF, Felippe Filho WN. An artificial multilayer perceptron neural network for diagnosis of proximal dental caries. Oral Surg Oral Med Oral Pathol Oral Radiol Endodontol. 2008;106:879-84.

27. Valizadeh S, Goodini M, Ehsani S, Mohseni H, Azimi F, Bakhshandeh H. Designing of a computer software for detection of approximal caries in posterior teeth. Iran J Radiol. 2015;12:42.

28. Lee J-H, Kim D-H, Jeong S-N, Choi S-H. Detection and diagnosis of dental caries using a deep learning-based convolutional neural network algorithm. J Dent. 2018;77:106-11.

29. Moutselos K, Berdouses E, Oulis C, Maglogiannis I. Recognizing occlusal caries in dental intraoral images using deep learning. In: 2019 41st annual international conference of the IEEE engineering in medicine and biology society (EMBC): IEEE; 2019. p. 1617-20.

30. Fukuda M, Inamoto K, Shibata N, Ariji Y, Yanashita Y, Kutsuna S, et al. Evaluation of an artificial intelligence system for detecting vertical root fracture on panoramic radiography. Oral Radiol. 2019;25:1-7.

31. Johari M, Esmaeili F, Andalib A, Garjani S, Saberkari H. Detection of vertical root fractures in intact and endodontically treated premolar teeth by designing a probabilistic neural network: an ex vivo study. Dentomaxillofac Radiol. 2017;46:20160107.

32. Kositbowornchai S, Plermkamon S, Tangkosol T. Performance of an artificial neural network for vertical root fracture detection: an ex vivo study. Dent Traumatol. 2013;29:151-5.

33. Hiraiwa T, Ariji Y, Fukuda M, Kise Y, Nakata K, Katsumata A, et al. A deeplearning artificial intelligence system for assessment of root morphology of the mandibular first molar on panoramic radiography. Dentomaxillofac Radiol. 2019;48:20180218.

34. Poedjiastoeti W, Suebnukarn S. Application of convolutional neural network in the diagnosis of jaw tumors. Healthc Inf Res. 2018;24:236-41.
35. Lee J-H, Kim D-H, Jeong S-N, Choi S-H. Diagnosis and prediction of periodontally compromised teeth using a deep learning-based convolutional neural network algorithm. J Periodontal Implant Sci. 2018;48:114-23.

36. Krois J, Ekert T, Meinhold L, Golla T, Kharbot B, Wittemeier A, et al. Deep learning for the radiographic detection of periodontal bone loss. Sci Rep. 2019;9:1-6.

37. Chang H-J, Lee S-J, Yong T-H, Shin N-Y, Jang B-G, Kim J-E, et al. Deep learning hybrid method to automatically diagnose periodontal bone loss and stage periodontitis. Sci Rep. 2020;10:1-8.

38. Kim J, Lee H-S, Song I-S, Jung K-H. DeNTNet: deep neural transfer network for the detection of periodontal bone loss using panoramic dental radiographs. Sci Rep. 2019;9:1-9.

39. Chen H, Zhang K, Lyu P, Li H, Zhang L, Wu J, et al. A deep learning approach to automatic teeth detection and numbering based on object detection in dental periapical films. Sci Rep. 2019;9:1-11.

40. Choi H-I, Jung S-K, Baek S-H, Lim WH, Ahn S-J, Yang I-H, et al. Artificial intelligent model with neural network machine learning for the diagnosis of orthognathic surgery. J Craniofac Surg. 2019;30:1986-9.

41. Wang C, Zhu X, Hong JC, Zheng D. Artificial intelligence in radiotherapy treatment planning: present and future. Technol Cancer Res Treat. 2019;18:1533033819873922.

42. Lee K-S, Ryu J-J, Jang HS, Lee D-Y, Jung S-K. Deep convolutional neural networks based analysis of cephalometric radiographs for differential diagnosis of orthognathic surgery indications. Appl Sci. 2020;10:2124.

43. Fukuda M, Ariji Y, Kise Y, Nozawa M, Kuwada C, Funakoshi T, et al. Comparison of 3 deep learning neural networks for classifying the relationship between the mandibular third molar and the mandibular canal on panoramic radiographs. Oral Surg Oral Med Oral Pathol Oral Radiol. 2020;130:336-43.

44. Jaskari J, Sahlsten J, Järnstedt J, Mehtonen H, Karhu K, Sundqvist O, et al. Deep learning method for mandibular canal segmentation in dental cone beam computed tomography volumes. Sci Rep. 2020;10:1-8.

45. Kim Y, Lee KJ, Sunwoo L, Choi D, Nam C-M, Cho J, et al. Deep learning in diagnosis of maxillary sinusitis using conventional radiography. Investig Radiol. 2019;54:7-15.

\section{Publisher's Note}

Springer Nature remains neutral with regard to jurisdictional claims in published maps and institutional affiliations.
Ready to submit your research? Choose BMC and benefit from:

- fast, convenient online submission

- thorough peer review by experienced researchers in your field

- rapid publication on acceptance

- support for research data, including large and complex data types

- gold Open Access which fosters wider collaboration and increased citations

- maximum visibility for your research: over 100M website views per year

At BMC, research is always in progress.

Learn more biomedcentral.com/submissions 